\title{
Evaluation of POSSUM for Patients Undergoing Pancreatoduodenectomy
}

\author{
S. M. M. de Castro $\cdot$ J. T. Houwert • \\ S. M. Lagarde $\cdot$ J. B. Reitsma $\cdot$ O. R. C. Busch . \\ T. M. van Gulik $\cdot$ H. Obertop $\cdot$ D. J. Gouma
}

Published online: 22 April 2009

(C) The Author(s) 2009. This article is published with open access at Springerlink.com

\begin{abstract}
Background Comparison of operative morbidity rates after pancreatoduodenectomy between units may be misleading because it does not take into account the physiological variable of the condition of the patients. The aim of the present study was to evaluate the Physiological and Operative Severity Score for the enUmeration of Mortality and Morbidity (POSSUM) for pancreatoduodenectomy patients and to look for risk factors associated with morbidity in a high-volume center.

Methods Between January 1993 and April 2006, 652 patients underwent a pancreatoduodenectomy, 502 of them for malignant disease. POSSUM performance was evaluated by assessing the "goodness-of-fit" with the linear analysis method.

Results Overall, 332 of the 652 patients (50.9\%) had one or more complication after pancreatoduodenectomy, and 9 patients (1.4\%) died. POSSUM had a significant lack of fit using goodness-of-fit analysis. In multivariate analysis, one statistically significant factor associated with morbidity and not incorporated in POSSUM $(P<0.05)$ was identified: ampulla of Vater adenocarcinoma $(\mathrm{OR}=1.73,95 \%$ CI: 1.07-2.80).
\end{abstract}

S. M. M. de Castro · J. T. Houwert · S. M. Lagarde

O. R. C. Busch - T. M. van Gulik · H. Obertop ·

D. J. Gouma ( $\square)$

Department of Surgery, Academic Medical Center,

Meibergdreef 9, 1105 AZ Amsterdam, The Netherlands

e-mail: d.j.gouma@amc.uva.nl

S. M. M. de Castro

e-mail: stevedecastro@gmail.com

\section{J. B. Reitsma}

Department of Epidemiology and Biostatistics, Academic

Medical Center, 1105 AZ Amsterdam, The Netherlands
Conclusions Overall, there is a lack of calibration of POSSUM among patients who undergo pancreatoduodenectomy.

\section{Introduction}

The Physiological and Operative Severity Score for the enUmeration of Mortality and Morbidity (POSSUM) has been successfully used as a tool to provide risk-adjusted operative morbidity and mortality rates for comparisons of surgeon and hospital performance [1-21]. Increased awareness of the hospital and surgeon volume effect has contributed to the use of such tools. The applicability has been further studied for various highly specialized procedures that include vascular $[6,9,13,22-26]$, pulmonary [27], head and neck [28, 29], orthopedic [30], emergency [7], esophageal [17], and liver procedures [5], and all of these applications have been derived from the original POSSUM [2].

There is limited literature on how POSSUM performs in patients undergoing pancreatoduodenectomy (PD). One study that used an adaptation, the Portsmouth-POSSUM, which analyzes mortality, found that this model appeared satisfactory for predicting mortality risk, but that the original POSSUM overestimated morbidity and mortality for PD [31]. These findings indicate that modifications are needed prior to further application. Furthermore, the study was hampered by the small number of patients and the fact that the Portsmouth-POSSUM does not analyze morbidity. Two more larger studies on original POSSUM for pancreatic surgery showed mixed results $[32,33]$.

The aim of the present study was to evaluate the predictive properties of POSSUM for morbidity in patients 
undergoing PD for periampullary neoplasms, and to identify specific risk factors associated with morbidity. The adapted version of POSSUM, the Portsmouth-POSSUM, which is used in the prediction of mortality was not analyzed because mortality is generally very low in highvolume centers.

\section{Patients and methods}

All patients who underwent PD for malignant and benign disease from January 1993 to April 2006 were included.
Patients were selected from our prospective database, and some of the variables needed to calculate POSSUM were collected retrospectively (Table 1). All patients were operated on by the same surgical staff during the study period.

Surgical procedure and complications

A PD was performed as previously described [34]. Briefly, an en bloc resection of the duodenum, pancreatic head, bile duct, and gallbladder was performed, and the pylorus was preferably preserved. Only lymph nodes surrounding the

Table 1 Physiological and operative severity assessment for the POSSUM system

\begin{tabular}{|c|c|c|c|c|}
\hline Score & 1 & 2 & 4 & 8 \\
\hline \multicolumn{5}{|l|}{ Physiological assessment } \\
\hline Age (years) & $\leq 60$ & $61-70$ & $\geq 71$ & NA \\
\hline $\begin{array}{l}\text { Cardiac signs } \\
\text { and/or }\end{array}$ & Normal & $\begin{array}{l}\text { Cardiac drugs } \\
\text { or steroids }\end{array}$ & Edema; warfarin & Raised JVP \\
\hline CXR & Normal & NA & Borderline cardiomegaly & Cardiomegaly \\
\hline $\begin{array}{l}\text { Respiratory signs } \\
\text { and/or }\end{array}$ & Normal & SOB exertion & SOB stairs & SOB rest \\
\hline CXR & Normal & Mild COAD & Moderate COAD & Any other change \\
\hline Systolic BP (mm Hg) & $110-130$ & $\begin{array}{l}131-170 \\
100-109\end{array}$ & $\begin{array}{l}\geq 171 \\
90-99\end{array}$ & $\leq 89$ \\
\hline Pulse (Beats/min) & $50-80$ & $\begin{array}{l}81-100 \\
40-49\end{array}$ & $101-120$ & $\begin{array}{l}\geq 121 \\
\leq 39\end{array}$ \\
\hline Coma score & 15 & $12-14$ & $9-11$ & $\leq 8$ \\
\hline Urea nitrogen $(\mathrm{mmol} / \mathrm{l})$ & $<7.5$ & $7.6-10$ & $10.1-15$ & $\geq 15.1$ \\
\hline $\mathrm{Na}(\mathrm{mEq} / \mathrm{l})$ & $\geq 136$ & $131-135$ & $126-130$ & $\leq 125$ \\
\hline $\mathrm{K}(\mathrm{mEq} / \mathrm{l})$ & $3.5-5$ & $\begin{array}{l}3.2-3.4 \\
5.1-5.3\end{array}$ & $\begin{array}{l}2.9-3.1 \\
5.4-5.9\end{array}$ & $\begin{array}{l}\leq 2.8 \\
\geq 6.0\end{array}$ \\
\hline $\mathrm{Hb}(\mathrm{g} / \mathrm{dl})$ & $13-16$ & $\begin{array}{l}11.5-12.9 \\
16.1-17\end{array}$ & $\begin{array}{l}10-11.4 \\
17.1-18\end{array}$ & $\begin{array}{l}\leq 9.9 \\
\geq 18.1\end{array}$ \\
\hline $\mathrm{WCC} \times 10^{12} / 1$ & $4-10$ & $\begin{array}{l}10.1-20 \\
3.1-3.9\end{array}$ & $\begin{array}{l}\geq 20.1 \\
\leq 3\end{array}$ & NA \\
\hline ECG & Normal & NA & AF $(60-90)$ & Any other change \\
\hline Operative severity assessment & & & & \\
\hline Operative magnitude & Minor & Intermediate & Major & Major+ \\
\hline No. of operations within 30 days & 1 & NA & 2 & $>2$ \\
\hline Blood loss per operation(ml) & $<100$ & $101-500$ & $501-999$ & $>1,000$ \\
\hline Peritoneal contamination & No & Serous & Local pus & Free bowel content, pus or blood \\
\hline Presence of malignancy & No & Primary cancer only & Node metastases & Distant metastases \\
\hline Timing of operation & Elective & & $\begin{array}{l}\text { Emergency resuscitation } \\
\text { possible, operation }<24 \mathrm{~h}\end{array}$ & $\begin{array}{l}\text { Emergency immediate, } \\
\text { operation }<2 \mathrm{~h}\end{array}$ \\
\hline
\end{tabular}

POSSUM formula: $\mathrm{Ln} \mathrm{R} / 1-\mathrm{R}=-7.04+(0.13 \times$ physiological score $)+(0.16 \times$ operative severity score $)$

In some variables, signs may be assessed clinically and/or by changes in results on chest X-ray film (CXR)

$N A$ not applicable, $J V P$ jugular venous pressure, $S O B$ shortness of breath, $C O A D$ chronic obstructive airway disease, $B P$ blood pressure, $N a$ sodium, $K$ potassium, $H b$ hemoglobin, $W C C$ white blood cell count, $E C G$ electrocardiogram, $A F$ atrial fibrillation 
pancreas anteriorly and posteriorly, in the hepatoduodenal ligament, and right of the common hepatic artery and portal vein and superior mesenteric vein were removed. If limited involvement of the portal vein or superior mesenteric vein was found, a (wedge) resection of the vein was performed with curative intent. The three anastomoses were generally made by bringing the proximal jejunal limb up along the retroperitoneum behind the mesenteric vessels or through the mesocolon. The pancreaticojejunostomy was generally constructed as an end-to-side anastomosis with a singlelayer 3-0 PDS running suture including the pancreatic duct. The hepaticojejunostomy was performed by a single-layer 3-0 PDS running suture, as was the gastrojejunostomy/ duodenojejunostomy. Morbidity was re-evaluated according to the criteria described by Copeland et al. [2].

Delayed gastric emptying, pancreatic leakage, and postpancreatectomy hemorrhage were registered according to recently suggested definitions established by the International Study Group of Pancreatic Surgery in the present study $[35,36]$.

\section{Statistical analysis}

A linear analysis was used to evaluate the predictive properties of POSSUM. For linear analysis as described by Whiteley et al. [18], patients were divided according to their predictive risk of morbidity. The number of patients falling into each such category was multiplied by the average risk of morbidity to give the predicted morbidity of that group. This type of analysis allows each group to be considered separately.

Statistical calculations were performed with SPSS software (Chicago, IL). A value of $P<0.05$ was considered significant. If missing data of a variable did not exceed $10 \%$ it was imputed in the database to maximize data extraction. A separate "missing data analysis" was performed to ensure that the data were missing at random. Analysis of specific risk factors associated with morbidity was done by the univariate method. Binominal variables where compared with the chi-square test. Categorical variables were compared with a reference variable by logistic regression. Continuous variables were also analyzed by logistic regression.

\section{Results}

The 652 two consecutive patients who underwent PD for various disorders during the study period were included in the present study (Table 2). There were nine postoperative deaths $(1.4 \%)$. One or more complications were seen in
Table 2 Characteristics of patients undergoing surgery for periampullary neoplasms

\begin{tabular}{|c|c|}
\hline & $(n=652)$ \\
\hline \multicolumn{2}{|l|}{ Gender } \\
\hline Male & $359(55)$ \\
\hline Female & $293(45)$ \\
\hline Median age (range) & $69(23-91)$ \\
\hline \multicolumn{2}{|l|}{ Procedure } \\
\hline Pyloric preserving pancreatoduodenectomy & $548(84.1)$ \\
\hline Kausch-Whipple pancreatoduodenectomy & $104(16)$ \\
\hline $\begin{array}{l}\text { Number of patients who underwent vascular } \\
\text { resection }\end{array}$ & $67(10)$ \\
\hline \multicolumn{2}{|l|}{ Pathology } \\
\hline Pancreatic adenocarcinoma & $233(35.7)$ \\
\hline Ampullary adenocarcinoma & $157(24.1)$ \\
\hline Distal common bile duct adenocarcinoma & $91(14)$ \\
\hline Pancreatitis & $72(11)$ \\
\hline Other malignant & $46(7)$ \\
\hline Other benign & $26(4)$ \\
\hline Duodenum adenocarcinoma & $14(2)$ \\
\hline Tubulovilleus adenoma & $13(2)$ \\
\hline Overall complications & $332(50.9)$ \\
\hline Delayed gastric empting & $139(21.3)$ \\
\hline Intra-abdominal abscess & $98(15)$ \\
\hline Pulmonary & $72(11)$ \\
\hline Pancreaticojejunostomy leakage & $59(9)$ \\
\hline Wound infection & $46(7)$ \\
\hline Hemorrhage & $46(7)$ \\
\hline Urinary tract infections and renal & $45(7)$ \\
\hline Cardiac & $39(6)$ \\
\hline Hepaticojejunostomy leakage & $20(3)$ \\
\hline Miscellaneous & $34(5)$ \\
\hline Number of patients who underwent a relaparotomy & $65(10)$ \\
\hline Median intensive care stay in days (range) & $1(0-84)$ \\
\hline $\begin{array}{l}\text { Median overall postoperative hospital stay in days } \\
\text { (range) }\end{array}$ & $15(6-222)$ \\
\hline \multicolumn{2}{|l|}{ Hospital stay for patients } \\
\hline With complications & $22(6-222)$ \\
\hline Without complications & $13(6-55)$ \\
\hline Mortality & $9(1.4)$ \\
\hline $\begin{array}{l}\text { Macroscopically radical resection in case of } \\
\text { malignancy }\end{array}$ & $336 / 502(66.9)$ \\
\hline
\end{tabular}

Numbers between parentheses are percentages unless indicated otherwise

332 of 652 patients $(50.9 \%)$. Missing data of the analysed variables never exceeded $10 \%$.

By means of linear analysis to compare predicted morbidity with observed morbidity, an O:P ratio of 0.88 was found (Fig. 1). POSSUM under-predicts actual morbidity in patients who are at low risk, and it over-predicts actual morbidity in patients who are deemed to be at high risk. 


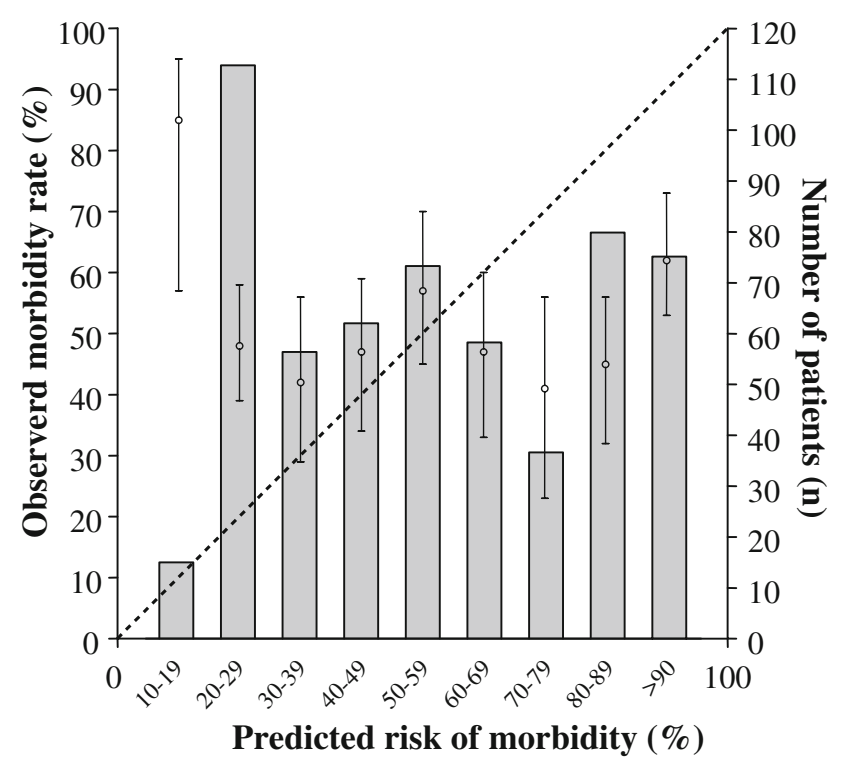

Fig. 1 Calibration curve of surgical morbidity (symbols with $95 \%$ confidence interval) showing significant deviation from the diagonal line, which represents a perfect predictive ability when the observed to expected ratio is 1.00 . The bars represent the number of patients in each risk group. (O:P ratio $=0.88, \chi^{2}=30.24,8$ degrees of freedom, $P<0.001$, indicating significantly poor fit)

The model had a significant poor fit $\left(\chi^{2}=30.24 ; 8\right.$ degrees of freedom [df]; $P<0.001)$.

Preoperative and perioperative variables associated with morbidity

The results of the univariate and multivariate analyses for preoperative and perioperative variables associated with morbidity are shown in Table 3. One factor from the original POSSUM was found to be an independent predictors of morbidity in the present data set, this was pulmonary history (Odds Ratio [OR] 2.05, 95\% Confidence Interval [CI] 1.15-3.67). Stepwise logistic regression also found that ampulla of Vater adenocarcinoma (OR 1.73, 95\% CI 1.07-2.80) was independently associated with morbidity. This factor is not incorporated in POSSUM.

\section{Discussion}

In the present study POSSUM failed to accurately predict morbidity. The results of the study cast serious doubt on the reproducibility of POSSUM in highly specialized procedures such as pancreatoduodenectomy. Modifications are needed prior to its application for a comparative audit in pancreatic surgery in high-volume centers.

Auditing instruments for evaluation of treatment outcome and quality of care between hospitals are required nowadays. Predicting morbidity with POSSUM has been evaluated in a general surgical population to enable a fair comparison between the population of individual surgeons and individual hospitals. The POSSUM system has recently undergone significant critical appraisal [37]. Copeland et al. [2], who described the original system and its application to general surgical patients, have reinforced its application for auditing outcomes in general and orthopedic surgery, comparing outcomes between units and for comparison of surgeons within an individual department, as well as monitoring for a change in an individual surgeon's performance over a period of years. There is no question concerning the usefulness of POSSUM for general surgery.

Khan et al. [31] were the first to evaluate POSSUM for pancreatic surgery, and they found that the model overestimated morbidity in a low-volume hospital. Their study was limited by the small number of patients. A more recent and lager study performed by Pratt et al. [33] found that the original POSSUM was a good predictor of morbidity and that the model had an excellent fit. Their study was conducted in a high-volume center, and they used the same statistical analysis methods applied in the present study. A possible reason for the different findings in our study and theirs could be the use of different definitions for what constitutes a postoperative complication. For example, the International Study Group on Pancreatic Fistula found that several definitions for pancreatic leakage after pancreaticodoudenectomy exist, and the reported range of $2-50 \%$ underscores this variation [36]. This is also the case for delayed gastric emptying and postoperative hemorrhage $[35,38]$. Together these three complications represent the majority of complications after pancreatic surgery, and differences in definition could explain the varied results of POSSUM.

In contrast, another large study performed by Tamijmarane et al. [32] found that POSSUM underestimated morbidity. Their study was performed in a high-volume hospital. The present study is the largest to date, and it found that POSSUM overestimates morbidity and has a significant lack of fit.

There are some known drawbacks to POSSUM [39], where pitfalls may be encountered in both data collection and data analysis. Data collection seems like a straightforward process, but methods have to be standardized if results are going to be reproducible. The physiological score is obviously subject to change over time, especially in nonelective urgent procedures. This was not a factor in the present study, which involves only elective procedures. Another problem could arise if the surgeon were to select the worst physiological score in order to show a positive result. Again, this is virtually impossible in the present study because the procedures were all performed electively, and the patients are presumed to have been 
Table 3 Univariate and multivariate analysis of variables found to be significantly associated with morbidity

\begin{tabular}{|c|c|c|c|c|}
\hline & $\begin{array}{l}\text { Patients } \\
(n=652)\end{array}$ & $\begin{array}{l}\text { No. of } \\
\text { complications }\end{array}$ & $\begin{array}{l}\text { Univariate unadjusted } \\
\text { odds ratio }(95 \% \mathrm{CI})\end{array}$ & $\begin{array}{l}\text { Multivariate adjusted } \\
\text { odds ratio }(95 \% \mathrm{CI})\end{array}$ \\
\hline Age (per 10-year increment) & & & $1.18(1.02-1.37)$ & \\
\hline \multicolumn{5}{|l|}{ Sex } \\
\hline Female & 293 & $132(45.1)$ & 1.00 & \\
\hline Male & 359 & $199(55.4)$ & $1.51(1.06-2.15)$ & \\
\hline BMI (per point increment) & & & $1.05(1.01-1.10)$ & \\
\hline \multicolumn{5}{|l|}{ Hypertension } \\
\hline No & 628 & $305(48.6)$ & 1.00 & \\
\hline Yes & 24 & $15(63)$ & $1.63(1.04-2.55)$ & \\
\hline \multicolumn{5}{|l|}{ Cardiac history } \\
\hline No & 616 & $296(48.1)$ & 1.00 & \\
\hline Yes & 36 & $22(61)$ & $1.74(1.13-2.70)$ & \\
\hline \multicolumn{5}{|l|}{ Pulmonary history } \\
\hline No & 552 & $267(48.4)$ & 1.00 & \\
\hline Yes & 100 & $68(68)$ & $2.29(1.32-3.98)$ & $2.05(1.15-3.67)$ \\
\hline Blood loss (per $100 \mathrm{ml}$ increment) & & & $1.02(1.00-1.04)$ & \\
\hline \multicolumn{5}{|l|}{ Type of tumor } \\
\hline Pancreatic adenocarcinoma & 233 & $107(46)$ & 1.00 & \\
\hline Ampulla of Vater adenocarcinoma & 157 & $93(59)$ & $1.72(1.08-2.73)$ & $1.73(1.07-2.80)$ \\
\hline Distal bile duct adenocarcarcinoma & 91 & $41(45)$ & $0.96(0.55-1.68)$ & \\
\hline Pancreatitis & 72 & $34(47)$ & $1.05(0.57-1.94)$ & \\
\hline Duodenum adenocarcinoma & 14 & $9(64)$ & $2.36(0.69-8.10)$ & \\
\hline Other malignancy & 46 & $22(48)$ & $1.06(0.53-2.14)$ & \\
\hline Other benign & 26 & $15(58)$ & $1.53(0.64-3.67)$ & \\
\hline Tubulovillus adenoma & 13 & $10(77)$ & $4.71(0.97-22.81)$ & \\
\hline
\end{tabular}

Numbers in parentheses are percentages unless indicated otherwise

Factors analyzed in univariate analysis that were not significant include: diabetes, American Society of Anesthesiologists classification, surgeon's experience, classical Whipple or pylorus-preserving pancreatoduodenectomy, transsection with surgical knife or linear stapler, use of multicomponent fibrin sealant, single or Roux-en-Y jejunal loop, one- or two layer anastomosis, drainage of pancreatic or biliary duct, packed cells transfused, use of octreotide and microscopic completeness of pancreatic resection plane in case of malignancy. Pancreatic texture was not scored regularly and was therefore omitted from the analysis

physiologically stable throughout the preoperative assessment. Furthermore, patients selected for a pancreatic resection are always subjected to intensive screening.

Missing data is another important problem in data collection. Some tests included in the POSSUM are not indicated in otherwise healthy individuals. Performing all these preoperative investigations is not in keeping with the hospital guidelines affecting the present study population. Therefore this study, like many others, scored these variables as 1 . However, missing data never exceeded $10 \%$ of the variables analysed in the present study. Also, analysis of the missing variables, including sole analysis of patients with the complete POSSUM work-up, showed that these data were indeed missing at random and did not influence the fit of the model.

Problems in data analysis can be due to the homogeneous nature of some variables. The operative score in the present study is homogeneous because the POSSUM is calculated for one procedure and thus does not vary much. In addition, all patients had the same operative severity score and the same mode of surgery-consistent with a single procedure-and they also had the same peritoneal soiling score. Only blood loss and the presence of malignancy differed among these patients.

Another point of discussion is which analysis method is best suited for POSSUM. Copeland et al. [2] have shown that exponential analysis continues to be predictive of mortality associated with general surgery. With linear analysis, small sample size can result in inaccurate results, and large samples will allow more accurate analysis of goodness-of-fit. Thus in the present study linear analysis was used because of the large sample size. Of interest, exponential analysis of the data from the present study (results not shown) yielded similar results.

Other highlighted potential pitfalls in the use of the POSSUM system include the classification of ECG 
abnormalities and the difficulty in establishing the exact operative blood loss [10].

Many patients undergoing surgery for periampullary neoplasms have major co-morbidity, which could strongly influence their risk of postoperative morbidity. This characteristic is not apparent in the POSSUM score in the present study because multivariate analysis did not find an association between these variables and postoperative morbidity. Technical complications do not seem to be influenced by preoperative factors, but they can reflect the extent of surgery and, perhaps, the surgeon's judgment. And as found in the present study and noted by many other authors, the degree of fibrosis of the pancreatic remnant (e.g., nondilated duct) seems to contribute significantly to the morbidity rate [40-46].

For most surgeons, their area of expertise dictates their highest-risk operative procedures. And many specialists have adapted POSSUM scoring as a way of allowing for case mix in their complex, high-risk operations. Separate equations have also been developed in specialized procedures. However, most adapted models are pending external validation. [The question remains if the specialized surgeons cannot suffice with regression analysis of their "casemix" in order to compare individual or hospital results.]

The outcome of the present study raises the question of whether a specialized POSSUM score has any place in pancreatic surgery because it is questionable whether an adequate model can be developed. It is also doubtful whether surgeons and clinicians are waiting for another "adapted model," as logistic regression analysis of their own data can be used for a similar purpose. Furthermore, the use of models that overpredict or underpredict morbidity may have grave consequences. Nevertheless, surgical audits are of the utmost importance, and if the use of POSSUM is desirable, our results point to a need for a new equation based on the variables that are unique to this procedure.

Open Access This article is distributed under the terms of the Creative Commons Attribution Noncommercial License which permits any noncommercial use, distribution, and reproduction in any medium, provided the original author(s) and source are credited.

\section{References}

1. Bennett-Guerrero E, Hyam JA, Shaefi S, Prytherch DR, Sutton GL, Weaver PC et al (2003) Comparison of P-POSSUM riskadjusted mortality rates after surgery between patients in the USA and the UK. Br J Surg 90:1593-1598

2. Copeland GP, Jones D, Walters M (1991) POSSUM: a scoring system for surgical audit. Br J Surg 78:355-360

3. Copeland GP, Sagar P, Brennan J, Roberts G, Ward J, Cornford P et al (1995) Risk-adjusted analysis of surgeon performance: a 1-year study. Br J Surg 82:408-411

4. Jones DR, Copeland GP, de Cossart L (1992) Comparison of POSSUM with APACHE II for prediction of outcome from a surgical high-dependency unit. Br J Surg 79:1293-1296
5. Lam CM, Fan ST, Yuen AW, Law WL, Poon K (2004) Validation of POSSUM scoring systems for audit of major hepatectomy. Br J Surg 91:450-454

6. Midwinter MJ, Tytherleigh M, Ashley S (1999) Estimation of mortality and morbidity risk in vascular surgery using POSSUM and the Portsmouth predictor equation. Br J Surg 86:471-474

7. Mohil RS, Bhatnagar D, Bahadur L, Rajneesh, Dev DK, Magan M (2004) POSSUM and P-POSSUM for risk-adjusted audit of patients undergoing emergency laparotomy. Br J Surg 91:500-503

8. Neary B, Whitman B, Foy C, Heather BP, Earnshaw J (2001) Value of POSSUM physiology scoring to assess outcome after intra-arterial thrombolysis for acute leg ischaemia (short note). $\mathrm{Br}$ J Surg 88:1344-1345

9. Neary WD, Crow P, Foy C, Prytherch D, Heather BP, Earnshaw JJ (2003) Comparison of POSSUM scoring and the Hardman Index in selection of patients for repair of ruptured abdominal aortic aneurysm. Br J Surg 90:421-425

10. Neary WD, Heather BP, Earnshaw JJ (2003) The physiological and operative severity score for the enumeration of mortality and morbidity (POSSUM). Br J Surg 90:157-165

11. Pillai SB, van Rij AM, Williams S, Thomson IA, Putterill MJ, Greig S (1999) Complexity- and risk-adjusted model for measuring surgical outcome. Br J Surg 86:1567-1572

12. Prytherch DR, Whiteley MS, Higgins B, Weaver PC, Prout WG, Powell SJ (1998) POSSUM and Portsmouth POSSUM for predicting mortality. Physiological and operative severity score for the enumeration of mortality and morbidity. Br J Surg 85:1217-1220

13. Prytherch DR, Sutton GL, Boyle JR (2001) Portsmouth POSSUM models for abdominal aortic aneurysm surgery. Br J Surg 88:958-963

14. Senagore AJ, Delaney CP, Duepree HJ, Brady KM, Fazio VW (2003) Evaluation of POSSUM and P-POSSUM scoring systems in assessing outcome after laparoscopic colectomy. Br J Surg 90:1280-1284

15. Tekkis PP, Kessaris N, Kocher HM, Poloniecki JD, Lyttle J, Windsor AC (2003) Evaluation of POSSUM and P-POSSUM scoring systems in patients undergoing colorectal surgery. Br J Surg 90:340-345

16. Tekkis PP, Prytherch DR, Kocher HM, Senapati A, Poloniecki JD, Stamatakis JD et al (2004) Development of a dedicated riskadjustment scoring system for colorectal surgery (colorectal POSSUM). Br J Surg 91:1174-1182

17. Tekkis PP, McCulloch P, Poloniecki JD, Prytherch DR, Kessaris N, Steger AC (2004) Risk-adjusted prediction of operative mortality in oesophagogastric surgery with O-POSSUM. Br J Surg 91:288-295

18. Whiteley MS, Prytherch DR, Higgins B, Weaver PC, Prout WG (1996) An evaluation of the POSSUM surgical scoring system. Br J Surg 83:812-815

19. Wijesinghe LD, Mahmood T, Scott DJ, Berridge DC, Kent PJ, Kester RC (1998) Comparison of POSSUM and the Portsmouth predictor equation for predicting death following vascular surgery. Br J Surg 85:209-212

20. Yii MK, Ng KJ (2002) Risk-adjusted surgical audit with the POSSUM scoring system in a developing country. Physiological and operative severity score for the enumeration of mortality and morbidity. Br J Surg 89:110-113

21. Zafirellis KD, Fountoulakis A, Dolan K, Dexter SP, Martin IG, Sue-Ling HM (2002) Evaluation of POSSUM in patients with oesophageal cancer undergoing resection. Br J Surg 89:11501155

22. Kuhan G, Abidia AF, Wijesinghe LD, Chetter IC, Johnson BF, Wilkinson AR et al (2002) POSSUM and P-POSSUM overpredict mortality for carotid endarterectomy. Eur J Vasc Endovasc Surg 23:209-211

23. Lazarides MK, Arvanitis DP, Drista H, Staramos DN, Dayantas JN (1997) POSSUM and APACHE II scores do not predict the 
outcome of ruptured infrarenal aortic aneurysms. Ann Vasc Surg 11:155-158

24. Myers NA (1993) Comparative vascular audit using the POSSUM scoring system. Ann R Coll Surg Engl 75:449

25. Shuhaiber JH, Hankins M, Robless P, Whitehead SM (2002) Comparison of POSSUM with P-POSSUM for prediction of mortality in infrarenal abdominal aortic aneurysm repair. Ann Vasc Surg 16:736-741

26. Yii MK (2003) Comparative audit of abdominal aortic aneurysm repairs using POSSUM scores. Asian J Surg 26:149-153

27. Brunelli A, Fianchini A, Gesuita R, Carle F (1999) POSSUM scoring system as an instrument of audit in lung resection surgery. Physiological and operative severity score for the enumeration of mortality and morbidity. Ann Thorac Surg 67:329-331

28. Cassia Braga RK, Kowalski LP (2003) APACHE II, POSSUM, and ASA scores and the risk of perioperative complications in patients with oral or oropharyngeal cancer. Arch Otolaryngol Head Neck Surg 129:739-745

29. Griffiths H, Cuddihy P, Davis S, Parikh S, Tomkinson A (2002) Risk-adjusted comparative audit. Is POSSUM applicable to head and neck surgery? Clin Otolaryngol 27:517-520

30. Mohamed K, Copeland GP, Boot DA, Casserley HC, Shackleford IM, Sherry PG et al (2002) An assessment of the POSSUM system in orthopaedic surgery. J Bone Joint Surg Br 84:735-739

31. Khan AW, Shah SR, Agarwal AK, Davidson BR (2003) Evaluation of the POSSUM scoring system for comparative audit in pancreatic surgery. Dig Surg 20:539-545

32. Tamijmarane A, Bhati CS, Mirza DF, Bramhall SR, Mayer DA, Wigmore SJ et al (2008) Application of Portsmouth modification of physiological and operative severity scoring system for enumeration of morbidity and mortality (P-POSSUM) in pancreatic surgery. World J Surg Oncol 6:39

33. Pratt W, Joseph S, Callery MP, Vollmer CM Jr (2008) POSSUM accurately predicts morbidity for pancreatic resection. Surgery 143:8-19

34. Obertop H, Pedrazzoli S (1999) Current views on surgical treatment of pancreatic cancer. Dig Surg 16:263-264

35. Wente MN, Bassi C, Dervenis C, Fingerhut A, Gouma DJ, Izbicki JR et al (2007) Delayed gastric emptying (DGE) after pancreatic surgery: a suggested definition by the International Study Group of Pancreatic Surgery (ISGPS). Surgery 142:761-768
36. Reid-Lombardo KM, Farnell MB, Crippa S, Barnett M, Maupin G, Bassi C et al (2007) Pancreatic anastomotic leakage after pancreaticoduodenectomy in 1,507 patients: a report from the Pancreatic Anastomotic Leak Study Group. J Gastrointest Surg 11:1451-1458

37. Jones HJ, de Cossart L (1999) Risk scoring in surgical patients. Br J Surg 86:149-157

38. Wente MN, Veit JA, Bassi C, Dervenis C, Fingerhut A, Gouma DJ et al (2007) Postpancreatectomy hemorrhage (PPH): an International Study Group of Pancreatic Surgery (ISGPS) definition. Surgery 142:20-25

39. Bann SD, Sarin S (2001) Comparative audit: the trouble with POSSUM. J R Soc Med 94:632-634

40. Yeo CJ, Cameron JL, Lillemoe KD, Sauter PK, Coleman J, Sohn TA et al (2000) Does prophylactic octreotide decrease the rates of pancreatic fistula and other complications after pancreaticoduodenectomy? Results of a prospective randomized placebo-controlled trial. Ann Surg 232:419-429

41. Stojadinovic A, Brooks A, Hoos A, Jaques DP, Conlon KC, Brennan MF (2003) An evidence-based approach to the surgical management of resectable pancreatic adenocarcinoma. J Am Coll Surg 196:954-964

42. Berge Henegouwen MI, de Wit LT, van Gulik TM, Obertop H, Gouma DJ (1997) Incidence, risk factors, and treatment of pancreatic leakage after pancreaticoduodenectomy: drainage versus resection of the pancreatic remnant. J Am Coll Surg 185:18-24

43. Hamanaka Y, Nishihara K, Hamasaki T, Kawabata A, Yamamoto S, Tsurumi M et al (1996) Pancreatic juice output after pancreatoduodenectomy in relation to pancreatic consistency, duct size, and leakage. Surgery 119:281-287

44. Sato N, Yamaguchi K, Chijiiwa K, Tanaka M et al (1998) Risk analysis of pancreatic fistula after pancreatic head resection. Arch Surg 133:1094-1098

45. Jimenez RE, Fernandez-Del Castillo C, Rattner DW, Warshaw AL (2003) Pylorus-preserving pancreaticoduodenectomy in the treatment of chronic pancreatitis. World J Surg 27:1211-1216

46. de Castro SM, Busch OR, van Gulik TM, Obertop H, Gouma DJ (2005) Incidence and management of pancreatic leakage after pancreatoduodenectomy. Br J Surg 92:1117-1123 